Volume 10 Issue 3

September 2019

\title{
The RIPPLES of Meaningful Involvement: A Framework for Meaningfully Involving Indigenous Peoples in Health Policy Decision- Making
}

\author{
Alycia J. Fridkin \\ University of British Columbia, alycia.fridkin@alumni.ubc.ca \\ Annette J. Browne \\ University of British Columbia School of Nursing, Annette.Browne@ubc.ca \\ Madeleine Kétéskwēw Dion Stout \\ University of British Columbia, madeleine_dion@hotmail.com
}




\title{
The RIPPLES of Meaningful Involvement: A Framework for Meaningfully Involving Indigenous Peoples in Health Policy Decision- Making
}

\begin{abstract}
Indigenous Peoples experience the greatest health inequities in Canada and other colonized countries; yet, they are routinely excluded from health-related policy decisions. Those advocating for Indigenous health equity are often left wrestling with the question: What constitutes, and what can foster, meaningful involvement of Indigenous Peoples in the contemporary health policy climate? Twenty $(n=20)$ in-depth, open-ended interviews with Indigenous and non-Indigenous leaders in health and health policy were conducted with a view to understanding what constitutes meaningful involvement of Indigenous Peoples in health policy decision-making. The analysis suggests meaningful involvement requires attuning to underlying power dynamics inherent in policy making and taking action to decolonize and transform the policy system itself. Based on these findings, the authors offer a framework for meaningful involvement.
\end{abstract}

\section{Keywords}

Indigenous, Aboriginal, First Nations, Indigenous health, Aboriginal health, health inequities, health, meaningful involvement, engagement, participation, policy, decolonization

\section{Acknowledgments}

The authors gratefully acknowledge the contributions of Jim Frankish, the research support from the Critical Research in Health and Healthcare Inequities Unit at the University of British Columbia's School of Nursing, and the funding received from the Canadian Institutes of Health Research's Institute of Indigenous Peoples' Health.

\section{Creative Commons License} (c) (1) (9)

This work is licensed under a Creative Commons Attribution-Noncommercial-No Derivative Works 4.0 License. 


\section{The RIPPLES of Meaningful Involvement: A Framework for Meaningfully Involving Indigenous Peoples in Health Policy Decision-Making}

Health and social inequities affecting Indigenous Peoples in Canada-namely, First Nations, Métis, and Inuit-have been consistently documented in key public health reports over the last several decades. Disparities exist across virtually every health indicator, including chronic disease, HIV, injuries, disabilities, mental health, problematic substance use, suicide, as well as social determinants of health such as housing, poverty, and employment (Browne et al., 2016; Brownridge, 2008; Nelson \& Wilson, 2017). These same disparities occur in other colonized countries, including Australia (Australian Institute of Health and Welfare, 2015; Dwyer, O'Donnell, Willis, \& Kelly, 2016) and New Zealand (Mitrou et al., 2014).

The literature suggests the consistency of these health inequities is hardly coincidental; it is the result of a history of colonial policies imposed on Indigenous Peoples from the moment of contact with European settlers. Wien (1999) argued that the history of Indigenous policy in Canada "is full of misguided policy choices," which have contributed to key factors affecting Indigenous Peoples' health, including the erosion of Indigenous economies and subsequent widespread poverty and starvation ( $\mathrm{p}$. 102). For example, the Indian Act confined First Nations Peoples to reserves, where infectious diseases thrived due to isolation and poor living conditions (Kelm, 1999). The residential school system played an equally traumatic role on the health of Indigenous Peoples. High rates of tuberculosis and untreated illness resulted in the death of many children, and the overall neglect, abuse, malnutrition, and detachment from families, language, and culture additionally contributed to the poor health of residents (Truth and Reconciliation Commission of Canada, 2015a). The separation of children from their families also had a devastating impact on Indigenous communities and continues to have traumatic intergenerational effects (Nelson \& Wilson, 2017). The Indian Act and residential school system, two policies that were made in isolation of Indigenous Peoples' perspectives or involvement, are examples of how a top-down approach to Indigenous health policy has contributed to health inequities between Indigenous Peoples and non-Indigenous peoples in Canada.

In the contemporary policy climate in Canada and globally, Indigenous Peoples have become more vocal about being involved in addressing health inequities; yet, health policy decisions are largely still made without involvement of Indigenous Peoples, and Indigenous women in particular (Dion Stout \& Kipling, 1998; Oliver et al., 2015), which contributes to ongoing health and social inequities (Fiske \& Browne, 2008; Howse \& Dwyer, 2016; Lavoie et al., 2016; Loppie Reading \& Wien, 2009). Some scholars argue that Indigenous Peoples' health and quality of life can only be improved if addressed on Indigenous Peoples' own terms, and there is a growing body of evidence showing that policies coproduced with Indigenous communities have better outcomes (Walker, Moore, \& Linklater, 2011). For example, in the Canadian context, the Transformative Change Accord in BC, a legal agreement between the provincial and federal governments and the First Nations Leadership Council, led to the creation of a First Nations Health Authority, where First Nations Peoples are able to provide health services based on a First Nations perspective of wellness (Gallagher, Mendez, \& Kehoe, 2015). In Ottawa and Winnipeg, municipal governments have worked with Indigenous communities in policy and planning co-production, which has been successful in fostering community acceptance and implementation (Belanger \& Walker, 2009). Indigenous Peoples' involvement in health policy has additionally been 
shown to improve Indigenous Peoples' health (Lavoie et al., 2010; Matthews, Pulver, \& Ring, 2008; Reading \& Nowgesic, 2002) as well as policy-making processes (Quantz \& Thurston, 2006).

When it comes to decision-making impacting Indigenous Peoples' health, there can also be value in including non-Indigenous peoples in the process. Regan (2005) argued that decolonization cannot be a project for Indigenous Peoples alone, as this is essentially asking Indigenous Peoples to take sole responsibility for healing themselves from the impacts of colonization. Aside from the ethical responsibility to address inequities created by their own governments, non-Indigenous peoples are appropriately positioned to disrupt their own colonial processes and may be key influencers in changing the status quo. Non-Indigenous people often occupy influential positions in government and/or act as gatekeepers, and when working in alignment with Indigenous Peoples, they may be an asset in overcoming systemic barriers.

In the Canadian context, Indigenous health policy is a complex environment. Historically, the federal government is responsible for providing health services and benefits to First Nations who are registered with the federal government as a "Status" First Nations person. For all other Indigenous Peoples, including non-Status First Nations, Métis, and Inuit, health services are provided in the same way as they are for the rest of the non-Indigenous population: financed by the national health insurance plan and administered by the provinces or territories. In addition, there are numerous policies, legislation, and agreements between different levels of governments, including Indigenous government organizations, in different parts of the country. This jurisdictional complexity has created many gaps and ambiguities in relation to who is responsible for Indigenous Peoples' health, and further contributes to the complexity of decision-making (National Collaborating Centre for Aboriginal Health, 2013).

There have been significant efforts and initiatives to involve Indigenous Peoples in health policy decision-making in Canada, including the Indian Health Transfer Policy in the 1980s (O'Neil, 1993), the Royal Commission on Aboriginal Peoples in the 1990s (Royal Commission on Aboriginal Peoples, 1996; Wien, 1999), the Kelowna Accord in the 2000s (DiPenta, 2006; Durbin, 2009; Patterson, 2006), and the Truth and Reconciliation Commission in 2015 (2015b). Each of these policy initiatives resulted in recommendations or calls to action, which include involving Indigenous Peoples in health policy decisions; yet, it is not clear what such involvement might look like nor what steps are needed to get there. Furthermore, Indigenous Peoples are becoming increasingly involved at high levels of decisionmaking (i.e., being engaged as a partner at senior government tables). What is not clear is how Indigenous leaders see these experiences and if they believe the nature of their involvement is actually meaningful or influential. As Indigenous Peoples continue to become more prominent in mainstream policy systems, there is a need to explore Indigenous involvement from the perspectives of both Indigenous and non-Indigenous peoples with lived experience at health policy decision-making tables.

Recognizing the need for clarity on what meaningful involvement looks like in the specific context of Indigenous health, the purpose of this article is to offer a framework and practical insights for meaningfully involving Indigenous Peoples in health policy decision-making. Drawing on findings from a qualitative study that explored Indigenous and non-Indigenous policy leaders' perspectives on what constitutes, and what can inform, meaningful involvement of Indigenous Peoples in health policy decision-making, we articulate a new conceptualization of meaningful involvement rooted in seven key 
elements. These findings have implications for policy making in other sectors and jurisdictions internationally.

\section{Literature Review: Indigenous Involvement in Health Policy}

For hundreds of years, Indigenous Peoples have been engaged in conversation with governments in order to resist oppressive policies and practices. However, throughout history and to the present day, the nature of engagement has remained largely colonial. Indigenous-government relationships are characterized by the domination of Eurocentric systems, whereby structural relations of power permeate engagement efforts (Coulthard, 2014). In policy domains such as treaty negotiations, land claims, natural resource extraction, and child welfare, Indigenous leaders have consistently demonstrated how inequitable power relationships restrict and define the terms of engagement, resulting in a widespread skepticism about the effectiveness of government engagements (Blackstock, 2011; Coulthard, 2014; Diabo, 2014; Palmater, 2014). Even when Indigenous Peoples are engaged with the explicit aim of autonomous decision-making or self-determination, such as self-government negotiations, the end result is often another iteration of colonialism and forced government dependence (Irlbacher-Fox, 2009).

In the context of health policy, Indigenous Peoples' involvement often occurs through processes that further perpetuate Indigenous Peoples' exclusion from decision-making. For example, governments commonly use community consultations as a method for gathering Indigenous Peoples' input on health issues, and in doing so tend to construct Indigenous Peoples as empowered and engaged citizens on one hand, while simultaneously undermining their power to make decisions on the other (Fiske \& Browne, 2008). Community consultations have resulted in the frequent failure of governments to include community input into policy decisions, which can devalue and delegitimize Indigenous Peoples' perspectives and foster cynicism about the false promises of inclusion (Fiske \& Browne, 2008; Howse \& Dwyer, 2016; Lavoie et al. 2015; McConaghy, 2000; Smye \& Browne, 2002). Government-initiated engagement processes have also been found to have harmful effects on Indigenous Peoples. These include misinterpretation of the priority issues (McConaghy, 2000; Smye \& Browne, 2002), misappropriation of Indigenous knowledges (Rains, Archibald, \& Deyhle, 2000), and political manipulation of Indigenous Peoples' input for solutions that may not align with community priorities (LaRocque, 2010). These critiques expose how discourses on involvement, such as "consultation," can become rhetoric that promotes the self-interests of governments and fails to address community issues of concern (Davidson, 2008; McWilliams, 2004).

Considering the ways Indigenous Peoples are typically involved in policy decision-making, Indigenous leaders have called for new terms of engagement. The United Nations Declaration of the Rights of Indigenous Peoples (UNDRIP; United Nations, 2007) outlines a vision for Indigenous Peoples' engagement on issues that affect them, including Indigenous Peoples' rights to determine their own priorities and to be actively involved in developing health and social programmes. Countries such as Canada have since endorsed the UNDRIP and have mandated implementation (Indigenous and Northern Affairs Canada, 2017). In the realm of research, Indigenous scholars have also developed policies and guidelines for involving Indigenous Peoples, such the $\mathrm{OCAP}^{\circledR}$ Principles, which declare the need for Indigenous ownership, control, access and possession of data, and were developed as an expression of Indigenous self-determination in research (First Nations Information Governance Centre, 
2019). Initiatives such as UNDRIP and $\mathrm{OCAP}^{\circledR}$ are relevant for thinking about how Indigenous Peoples could be more meaningfully involved in research and policy.

\section{Research Design and Methods}

In response to Indigenous Peoples' repeated calls to be meaningfully involved in health policy decisionmaking (Coulthard, 2014; Lavoie, Boulton, \& Gervais, 2012; Matthews et al., 2008) and the gaps in the literature on how this can be achieved, this study aimed to provide further clarity into how meaningful involvement of Indigenous Peoples in health policy decision-making might be conceptualized, and further, how this could be achieved. The specific research objectives were:

a. To explore, from the perspectives of leaders and decision-makers in Indigenous health and other areas of Canadian health policy, what constitutes meaningful involvement of Indigenous Peoples in health policy decision-making; and

b. To develop recommendations for meaningfully involving Indigenous Peoples in health policy and decision-making processes in Canada and beyond.

To address these objectives, 20 in-depth, open-ended interviews with leaders and decision-makers in Indigenous health and other health policy areas in Canada were conducted. The study was qualitative and exploratory in nature, and the focus of the interviews was on exploring participants' experiences in health policy decision-making related to Indigenous Peoples' health as well as these leaders' perspectives on what constitutes meaningful involvement. The study received ethical approval through the University of British Columbia's Behavioral Research Ethics Board (BREB). In accordance with current Canadian guidelines on research involving Indigenous Peoples (Government of Canada, 2017), this research was designed to focus on an issue of major priority to Indigenous Peoples, and the lead investigators included Indigenous (Dion Stout) and non-Indigenous (Fridkin \& Browne) scholars with extensive experience on the research topic. Fridkin was the primary researcher and lead the data collection, analysis, and writing, and Dion Stout and Browne provided direction on the overall research study, including participant recruitment, data analysis, and interpretation of findings.

The analysis and research design were informed by a theoretical framework rooted in perspectives that are attuned to issues of equity and relations of power within social and political structures. We included Indigenous and decolonizing perspectives, which focus on disrupting the dominance of Eurocentric perspectives, foregrounding Indigenous histories and narratives, and advancing Indigenous justice agendas (Battiste, 2009; Battiste \& Youngblood Henderson, 2000; Denizen, Lincoln, \& Smith, 2008; Ermine, 1999, 2007; Regan, 2005; Rigney, 1999; Smith, 1999; Turner, 2006). We further developed our analysis from critical theoretical perspectives such as postcolonial feminism, which focuses on disrupting "race-thinking" and drawing attention to how colonialism, race, ethnicity, culture, and gender shape inclusion, exclusion, and inequities (Anderson, 2000; Asher, 2017; Browne, Smye, \& Varcoe, 2007). These theoretical perspectives shaped every aspect of the research, including the development of the research questions and methodology. For example, decolonizing perspectives were used to orient the research objectives towards issues of relevance and interest to Indigenous Peoples, and critical perspectives such as postcolonial feminism, intersectionality, and cultural safety were used to focus the analysis on the underlying power inequities that shape policy processes and Indigenous Peoples' inclusion, as well as Indigenous Peoples' experiences of safety at the policy decision-making table. 
To capture a range of perspectives and insights on meaningful involvement in various policy contexts, we recruited participants who were working in positions related to Indigenous health across a range of governmental, organizational, and policy levels, paying attention to gender diversity. Both Indigenous and non-Indigenous participants were interviewed for two reasons:

a. To explore a range of perspectives and experiences related to Indigenous Peoples' involvement in policy, based on the recognition that socio-political positioning influences a person's experiences and perspectives; and

b. To include a sample that was somewhat reflective of the population of people working in Indigenous health policy settings, which includes both Indigenous Peoples and nonIndigenous peoples.

The sampling strategy involved a combination of purposive and convenience sampling (see Barbour, 2001; Thorne, 2008). The research team identified people in their social networks who met the inclusion criteria, would have good insight on the research topic, and were positioned to provide insight on "what is happening and why it is happening" in the context of Indigenous health policy (Thorne, 2008, pp. 89-91). These individuals were invited to participate in an interview. The study participants were leaders, decision-makers, or experts with significant experience working in Indigenous health or public health policy. Participants were located in geographic locations across Canada and held a range of leadership positions, including directors $(n=11)$, senior leaders $(n=6)$, managers or team leads $(n=2)$, and professors in health disciplines $(n=1)$. Half of the participants $(n=10)$ self-identified as Indigenous, approximately half self-identified as White, Euro-Canadian, and/or European $(n=9)$, and one $(n=1)$ self-identified as having mixed Indigenous and European ancestry. Approximately half of participants self-identified as women $(n=11)$ and half identified as men $(n=9)$. The age range of participants was between 47 and 76 years, with a mean age of 57 years. Participants were highly educated with many participants $(n=15)$ who had completed a graduate degree at the time of the interview and approximately half $(n=9)$ who had professional designations in nursing, medicine, dentistry, or law.

The interview guide was developed at the outset and further refined in response to emerging themes and insights gained from conducting the interviews. The questions were open-ended and exploratory in nature and sequenced with the intent of evolving from an information-based conversation to an in-depth discussion.

Data collection and analysis were guided by a research team comprised of Indigenous and nonIndigenous researchers with extensive experience in Indigenous health policy research in Canada. The study was conducted between 2012 and 2015 and ethical approval was provided throughout this time period.

The interview and field note transcripts were organized using NVivo qualitative data analysis software, which included coding each transcript based on a codebook of topic-based codes developed from an analysis of initial reflections and subsequent readings of the data. A thematic analysis involving an inductive process of systematically reading and re-reading the data alongside the development of an evolving coding structure supported a more in-depth thematic analysis of emerging themes and insights. Subsequent levels of analysis involved articulating new conceptualizations arising from the data, which 
were informed by the guiding theoretical perspectives and research questions (Richards \& Morse, 2007; Thorne, 2008).

To establish trustworthiness of the data, two participants were invited to dialogue with the primary researcher with respect to the analysis and the key elements of meaningful involvement identified through the research. Since the purpose of these follow-up discussions was to get an overall sense of the relevance of the analysis and the representation of the findings, and whether or not they resonated with participants, as opposed to assessing the accuracy of how each participant's views were captured in the analysis, efforts were made to solicit meaningful feedback from a few select participants rather than systematically reviewing the findings with each participant. In particular, two Indigenous participants with extensive policy experience who were working in Indigenous health leadership roles within a large organization provided critical feedback and indicated that the overall thrust of the findings resonated with their experiences and represented a coherent account of the complexity of meaningful involvement in policy making.

\section{Findings}

The findings are organized into three sections:

a. Wrestling with uncertainty, describing participants' questioning on how to involve Indigenous Peoples in various settings;

b. Attuning to power dynamics, drawing on participants' lived experiences at the decisionmaking table to illustrate the ways power inequities play out in policy and decision-making processes; and

c. Perspectives on meaningful involvement, outlining participants' insights on what has worked, what has not, and what is needed for involving Indigenous Peoples in more meaningful ways.

\section{Wrestling with Uncertainty: Immobilized by Sensitivity to “Doing the Wrong Thing”}

Participants recognized the need to meaningfully involve Indigenous Peoples and reflected on the challenges. Many non-Indigenous participants wrestled with the question of how to meaningfully involve Indigenous Peoples in the face of historical and ongoing colonization. One non-Indigenous participant explains:

Well I think that one of the big issues, of course, is the whole issue of [colonization] ... How it also shapes the policies that we have in this country ... [H] ow do you back away from a colonial sort of attitude ... in relationships and build a trusting relationship between the Aboriginal and non-Aboriginal communities so that we can be working together on these public health issues? (P08)

In wrestling with questions such as these, the participants echoed LaRocque's (2010) stated belief, "the majority of non-Native peoples in our country want to be fair and caring, not just replicating a history full of mistakes and some malefaction ... Nevertheless, our encounter is informed by colonization" ( $\mathrm{p}$. 14). Some Indigenous participants discussed the good intentions on the part of non-Indigenous people working in policy to find ways of involving Indigenous Peoples in more meaningful ways; yet, despite 
such intentions, the historical and ongoing nature of colonialism was identified by both Indigenous and non-Indigenous participants as a significant stumbling block to working together.

Although the participants displayed an acute awareness of the impact of colonialism on Indigenous and non-Indigenous encounters in policy decision-making, their interviews reflected an uncertainty about how to navigate these dynamics. This is illustrated in a debate within a health policy advisory group, which one non-Indigenous participant describes:

[W] hen the [group] first formed, one of its goals was to pay special attention to Aboriginal Peoples' health. That was part of their mandate from the beginning and they never did it. There were endless arguments about, how are we going to incorporate that? Would we have Aboriginal representation in the [group]? If we did that, do we need it at all levels of the [group], not only at the general [group's] table but at the expert groups as well? Who would you choose? Who's credible? How would you keep this from being political? This argument went on and on and on and no-one could come to a conclusion. (P19)

P19 continues to share an analysis of what underlies such debates:

[I]n Canada people who work in health who haven't worked with First Nations people aren't comfortable working with First Nations people ... [They] are very reluctant to make decisions because they want to be very sensitive that they don't do the wrong thing. And in being so sensitive to doing the wrong thing, they never do the right thing. Because they feel so timid and cautious. (P19)

Like P19, other Indigenous and non-Indigenous participants explained how there is often a hesitancy to include Indigenous Peoples in decision-making that arises from a variety of fears, including making the wrong decisions, crossing jurisdictional boundaries, and receiving backlash from Indigenous communities. Several participants discussed the tendency for decision-making between Indigenous Peoples and non-Indigenous peoples to be uncomfortable, and some participants explain that this discomfort stems from the legacy of colonialism and the history of tensions between Indigenous Peoples and governments. These discussions illustrate how the "psychology of colonialism lingers" in policy settings, (LaRocque, 2010, p. 6), and how policy decision-making environments may be illustrative of what LaRocque (2010) described as "the contested ground upon which we, the Canadian colonizercolonialist and Native colonized, have built our troubled discourse" (p.3).

Although non-Indigenous participants wrestled with these uncertainties of knowing how to include Indigenous Peoples, some Indigenous participants reiterated the need to find ways of working through these challenges. As one Indigenous participant asserts, "Aboriginal representation ... [is] extremely difficult to do ... at a policy meeting table, but it has to be [done]" (P17). In referring to Indigenous representation as "extremely difficult to do," this participant may be reflecting some of the challenges with representation that the non-Indigenous participants described above, such as trying to determine who should be included and how, and considering the colonial context that continues to permeate Indigenous and non-Indigenous relationships. Drawing from LaRocque's (2010) assertion that both Indigenous Peoples and non-Indigenous peoples "are challenged to attend to decolonization while keeping with our respective legacies," and that ending Indigenous Peoples' marginalization in society must be a "collective aspiration" (p. 14), the interviews highlight the need for insight on how to foster an 
environment where Indigenous Peoples and non-Indigenous peoples can work together within the colonial context towards a common policy goal.

\section{Elbows Up, Shutting Down: Attuning to Power Dynamics}

Participants' lived experiences at policy decision-making tables revealed several ways underlying power dynamics play out at the decision-making table. One example of this is the inherent clash of paradigms that can be experienced when Indigenous Peoples participate in Eurocentric decision-making processes. The interviews illustrate how decision-making tables are often more suited to dominant norms operating in government about how meetings ought to proceed. One Indigenous participant (P09) explains, "it's pretty common in the Aboriginal community to find people ... [who] are reflective. We want time to think about ... things. But we're against the clock.” P09 further explains:

[T] he way that the meetings are run ... you've got two hours, you've got this much agenda... you have to butt in and interrupt if you want to get something said. I'm so uncomfortable doing that ... [I]t completely goes against my nature and I think this is a cultural nature that $\mathrm{I}$ have ... I use that expression "elbows up" ... [A]nd it's so against my nature to be able to do it. So that is really, really difficult. (P09)

Indigenous participants also discussed how common it was for them to be the only Indigenous person in the room and how this posed significant challenges when discussing Indigenous issues. P09 describes being repeatedly asked to participate in meetings and speak to issues from an Indigenous person's perspective:

I have to have a little bit of their knowledge plus Aboriginal knowledge, right? ... It's hard to be an expert in everything, which is their expectation of me. And so it's easy for them [the people at the table] to shut me down because they have more specific knowledge in their specific area than I do. (P09)

These dynamics create a situation where even though an Indigenous person is invited to participate in meetings to provide expertise on Indigenous health, a hierarchy of knowledge systems creates an environment that makes it easy for Indigenous individuals to be shut down at the table.

The interviews further suggest that Indigenous Peoples are uniquely implicated when participating in decision-making on Indigenous health issues, in that they are socially and politically located in the centre of the policy problem. Indigenous participants explained how they often have to actively strategize on ways of bringing up the tough issues, such as racism, and how this can be exhausting, isolating and painful. Reflecting on some participants' observations that Indigenous individuals will stop coming to meetings, P09 suggests, "Maybe [Indigenous people] don't come because it's ... so uncomfortable. And maybe they're just not feeling strong enough to be the conveyor of that message today." These data illustrate how Indigenous Peoples are inequitably positioned at policy decision-making tables, and how these dynamics can create situations that push Indigenous individuals away from participating in the process altogether.

These findings may shed light on recent situations in Canadian politics where Indigenous leaders have resigned or stepped down from leadership positions due to intense public and political pressures, 
bullying, or government refusal to adhere to their recommendations (see Atleo, 2014; Scott, 2019). When examining such situations in light of the analysis discussed in this article, Indigenous leaders' resignations can be understood within the context of policy environments that are often uniquely violent towards Indigenous Peoples who participate in them. Considering these effects, a key factor enabling meaningful and sustainable involvement of Indigenous Peoples in health policy decision-making, is the way in which processes of involvement mitigate the effects of underlying power inequities. This includes recognizing and addressing power dynamics that contribute to Indigenous Peoples' withdrawal and resignation from decision-making, and that ultimately foster Indigenous Peoples' exclusion.

\section{The Tokenism Paradox: Perspectives on Meaningful Involvement}

In sharing their perspectives on what constitutes meaningful involvement, participants provided many insights on how to involve Indigenous Peoples in meaningful ways. For example, several participants described how there was a tendency for Indigenous individuals to be involved in decision-making in tokenizing ways, which some participants described as problematic. One Indigenous participant (P12) explains how Indigenous involvement often takes the form of "someone holding a feather or having an Elder come to do an opening prayer," which can have, "deep spiritual meaning [for Indigenous Peoples], but have very superficial effects on White people." While commenting on the tendency for Indigenous Peoples to be primarily included in cultural ways, another Indigenous participant shares:

I worry that there's a danger of us [Indigenous people] tokenizing ourselves by putting [culture] as the number one thing that you can do. It's easy to do, it costs you five minutes at your meeting, you don't have to spend any money and, "Oh there we're done. We included Aboriginal people." (P09)

Dion Stout (2008) suggests although Indigenous cultural practices are often important to Indigenous Peoples' identities, "this view becomes too narrow when it suggests that no one has to work hard on the non-cultural (social, political, economic) aspects of our lives" (p. 11). Inviting Indigenous Peoples to participate solely in cultural ways may thus perpetuate the construction of Indigenous Peoples as primarily cultural beings and undermines the broad range of perspectives and knowledges Indigenous Peoples may contribute to policy development and decision-making.

Despite participants' criticisms of the tendency for Indigenous individuals to be involved as, in one Indigenous participant's words, "token Indians" who are "not allowed to do anything" (P16), the interviews also suggest tokenism may present an opportunity for involvement. One Indigenous participant explains:

We cannot become ... complicit with the appetite for tolerance... [But] in some spaces, that tokenism is a giant step forward. However ... we can't stop there ... [Y] ou've got to start where they're at, but it doesn't mean you've got to expect less. Like prayer today, [but] how about next year we do something really radical, you know, besides a prayer. (P12)

The perspective shared by this participant seems paradoxical: On the one hand, tokenism is problematic in that it can perpetuate the view that simply inviting an Indigenous person to the table is enough, or that Indigenous Peoples only need to be included for the purpose of fulfilling presumed ideas about infusing meetings with a cultural element; yet, on the other, tokenism can be viewed as a potential opportunity 
for Indigenous Peoples to have a seat at the table, especially when Indigenous Peoples have not been involved at all. When the fear of tokenism is used as justification to not include Indigenous Peoples at all, the tokenism paradox can be a helpful perspective in weighing the costs of tokenism versus the status quo of zero involvement.

Importantly, several participants spoke about the need to move beyond tokenism in order to involve Indigenous Peoples in more influential ways. One participant who identified as being of mixed Indigenous and European ancestry explains:

$[Y]$ ou can't just think that in some kind of band aid way you get an Indigenous person to the table and it's gonna have any kind of influence. Because there's such a risk of tokenism and such a risk of [thinking], now we've included Aboriginal people so therefore this ... must be a better policy, not necessarily ... [J] ust because you're Aboriginal doesn't mean that you think outside of the dominant way of thinking. You know you can have somebody at the table that's just as capable of saying, "Oh, Aboriginal people should just pull up their socks as their Euro Canadian counterparts.” (P01)

In addition to critiquing the assumption that including one Indigenous person will lead to better decisions, the findings highlight the need to involve Indigenous individuals who view Indigenous issues with an analytical lens that challenges dominant ways of thinking, and who are attuned to the structural forces that shape health and health inequities.

The interviews also emphasized the need to focus on relationships between Indigenous and nonIndigenous parties involved in decision-making. Participants spoke about tensions that exist as a result of colonial dynamics and shared examples of what has helped to build trust and good working relationships. One non-Indigenous participant (P06) explained how this process incited a shift in relationship between the parties, which resulted in the Indigenous group moving from an advisory role to becoming a partner in decision-making. Other participants talked about the nature of partnership required for Indigenous Peoples and non-Indigenous peoples to work together effectively. As this participant, who identified as Indigenous, describes:

$[\mathrm{Y}]$ our players also have to be [engaged in] reciprocity [which] is very much ... about personality. It's the notion that you are true partners. When I talk about reciprocity... I mean very much the notion of having the right attitude, being committed to it, knowing that each are giving something and ... both [government and Indigenous] partners are winning in this. (P20)

These findings point to the attitudes and sense of commitment among those involved as a significant factor in overcoming the stumbling block of historical and ongoing colonialism, reconciling relationships, and working together in ways that are different from the past.

In their discussions on what enables meaningful involvement, several participants spoke about the impact of formalized agreements between Indigenous and non-Indigenous parties. One Indigenous participant explains:

We are attached to the [provincial agreement], if we didn't have that we would have flat burnt out, we never would have gone anywhere... The business case $[$ is $]$ not good enough when it 
comes to Aboriginal issues. You have to have something really powerful to force people because if we didn't have that, it wouldn't happen. (P12)

As in the example above, several Indigenous participants talked about the importance of formalized agreements as key documents that held governments accountable to including Indigenous Peoples and confirming that Indigenous Peoples' voices were heard. Another Indigenous participant shares:

We're not advisors in our own health, we are decision-makers ... that's in the principles of the agreement. So whenever someone at the table says something like "we're not allowed to change the form, we're not allowed to change the policy, [or] we can't do it like that," the principles of the agreement [allow us]. (P17)

The participants explained that effective formal agreements are not merely symbolic gestures of government commitments to including Indigenous Peoples and addressing Indigenous health issues; they are legal documents that hold governments accountable to fulfilling their commitments. Both Indigenous and non-Indigenous participants also shared how agreements have often led to establishing protocols and ways of working together that enable better participation. These findings resonate with the findings in Cheema's (2007) study, which show that "multi-directional accountability relationships" are a key factor in supporting the meaningful participation of Indigenous Peoples in health policy and planning (p. 29).

Indigenous participants explained how the agreements enable access to high-level decision-making tables that are typically inaccessible, which create situations where Indigenous Peoples have the ear of decision-makers. Similarly, a non-Indigenous participant explained that the influence of "champions" at senior levels of government has been helpful in pushing forward Indigenous health agendas (P06). These data suggest that the involvement of high-level decision-makers may not only have an impact on the potential of decision-making processes to effectively change policy, but that this can facilitate Indigenous issues getting on the policy agenda. In this way, the interviews reveal how legislating Indigenous involvement can be a way of leveraging power: It compels those in power to take Indigenous Peoples' agendas seriously.

The data demonstrate that involving Indigenous Peoples in policy decision-making in more meaningful ways requires change at a deep structural level. One Indigenous participant explains, "really what we're talking about is change," and further clarifies, "I'm talking about change that goes to the guts of the organization [in] how they think and how they act, and that requires doing things in a different way" (P12). Although participants emphasized the challenges of trying to achieve this kind of structural change, they also reiterated the necessity for working towards this goal, as one Indigenous participant asserts, "This change has to come... We can no longer say it can't be done" (P16). The findings emphasize the need to articulate ways of disrupting the status quo approach of policy decision-making and achieving structural change, as this is needed to foster Indigenous Peoples' involvement at a more meaningful and influential level. 


\section{Discussion: What Constitutes Meaningful Involvement?}

There are several significant key findings that emerged from this research:

a. Even when the importance of involving Indigenous Peoples in decision-making is realized, the lack of clarity on what involvement should look like can prohibit any kind of involvement at all.

b. When Indigenous Peoples are involved in a decision-making process, the inherent power imbalances between Indigenous Peoples and non-Indigenous peoples and ongoing colonial dynamics shape the experience of Indigenous Peoples participating in the process and limit the extent of involvement.

c. While involving Indigenous Peoples in ways that may be viewed as tokenizing can serve as a significant first step towards more meaningful involvement, there is a clear need to move beyond tokenism. Meaningful involvement requires including Indigenous Peoples in more than only cultural ways (e.g., providing a cultural opening to a meeting), a commitment by all parties to reconcile relationships and work together in new ways, and formal agreements that mandate the inclusion of Indigenous Peoples and assert a mutual responsibility for decisions made.

A critical analysis of the data reveals that meaningful involvement is often experienced as a paradox where Indigenous Peoples are excluded via processes of inclusion, and that fostering meaningful involvement requires attuning to the underlying power dynamics inherent in policymaking and taking action to decolonize and transform the policy system itself. This research provides insight into Smye and Browne's (2002) question of whether or not Indigenous Peoples are involved in processes that "espouse the benefits of reform, in the absence of real material gains for aboriginal people" (p. 52). In order to inform thinking on how decision-making processes can become more meaningful, less harmful, and more beneficial to Indigenous Peoples, we need to conceptualize meaningful involvement in a way that considers how colonial dynamics shape the experience of Indigenous Peoples who are involved.

In light of this consideration, we draw on the research findings to articulate a new conceptualization of meaningful involvement. The interviews point to the importance of involving Indigenous Peoples in ways that are not harmful and do not subsequently lead to withdrawal from process, but instead mitigate the multiple and sometimes covert ways racism and inequitable power dynamics play out at decisionmaking tables and throughout decision-making processes. In this sense, meaningful involvement means challenging and disrupting the status quo; it connotes an approach to decision-making that is transformative and decolonizing in its aim to disrupt the systemic exclusion of Indigenous Peoples from policy processes. These insights gained from the research as a whole inform thinking on what constitutes the key elements of meaningful involvement.

\section{The Key Elements of Meaningful Involvement}

To articulate a new conceptualization of meaningful involvement that is attuned to underlying power inequities and disrupting the status quo, we describe seven evidence-informed key elements of meaningful involvement based on a thematic analysis of the data: 
a. Recognizing and Representing Indigenous Peoples - recognizing or acknowledging Indigenous Peoples and/or territories and taking efforts to have Indigenous Peoples represented at decision-making tables, even if tokenism seems like a false start and not a head start;

b. Interrupting and Re-Imagining Relationships - actively interrupting the ways Indigenous Peoples and governments have historically worked together and re-defining working relationships based on a process of reconciliation;

c. Preparing Agreements - establishing formal, written agreements between parties that articulate the nature of working relationships, mandate Indigenous involvement in the process, commit both parties to sharing responsibility for addressing Indigenous health issues, and hold parties jointly accountable for the decisions made in the process;

d. Practicing Protocols - developing and implementing rules for Indigenous Peoples' engagement in the process, as well as protocols to guide how the parties will work together and enact the relationships set out in formal agreements;

e. Leveraging Power - taking efforts to foster a process that has the necessary power and sufficient capacity to make and implement health policy decisions, such as engaging the highest-level decision-makers in the process;

f. Exerting Community Authority - taking explicit efforts to foster a process that is being driven by Indigenous community members, namely, Indigenous individuals who are most connected to and familiar with the issues being addressed and who solely represent a community perspective; and

g. Shifting Social Structures - taking efforts towards addressing the systemic barriers impeding Indigenous Peoples' involvement in policy, such as explicit efforts to incorporate Indigenous paradigms and include, support and protect Indigenous individuals in high-level positions in the mainstream policy system.

While each of these key elements is rooted in the data collected for this project, they also align with perspectives in the literature. For example, the writings of Indigenous and non-Indigenous activists serve as a reminder that Indigenous Peoples' attempts to engage with governments are still often ignored (The Kino-nda-niimi Collective, 2014), which highlights the importance of Recognizing and Representing Indigenous Peoples. Reconciling and rebuilding relationships between Indigenous Peoples and nonIndigenous peoples have been shown to play a critical role in the way Indigenous Peoples are involved in decision-making (Cheema, 2007), which supports Interrupting and Re-Imagining Relationships. Walia (2015) and Regan (2005), among others, argue that non-Indigenous peoples have a responsibility for decolonizing themselves and taking action to address Indigenous justice issues, which underscore the emphasis on non-Indigenous peoples' responsibility and accountability in Preparing Agreements. Ermine (2007) describes the need for clear rules of engagement to guide ethical interactions between Indigenous Peoples and non-Indigenous peoples, which is reflected in Practicing Protocols. Lessons learned from the creation of Indigenous health institutions have demonstrated the importance of working with senior government partners (Gallagher et al., 2015), which supports the ideas within Leveraging Power. Turner (2006) and others assert that Indigenous Peoples need to determine who participates in processes or dialogues, which supports the goals of Exerting Community Authority. Finally, Indigenous and non-Indigenous scholars have called for the inclusion of Indigenous Peoples and knowledges in mainstream institutions as a way of decolonizing policy systems (Fridkin, 2012; Turner, 2006), which aligns with the objectives of Shifting Social Structures. 
Each of these elements may be understood as existing along a continuum, where each element builds on the previous one so that Indigenous Peoples are increasingly influential in the process. Conceptualizing meaningful involvement as a continuum may help draw attention to the ways in which Indigenous Peoples are, and could be, more meaningfully and influentially involved. We also caution that these elements are not intended to represent a prescriptive list of criteria for what meaningful involvement will look like at every stage of every decision-making process, rather they are intended to inform thinking on how decision-making processes could involve Indigenous Peoples in more meaningful and influential ways. Table 1 further articulates what each element entails and illustrates how each could be enacted in a policy decision-making process.

\section{RIPPLES: A Framework for Meaningful Involvement}

To facilitate an understanding of how enacting these elements of meaningful involvement could contribute to transforming and decolonizing health policy decision-making processes, we illustrate these elements in relation to each in Figure 1. We refer to this framework as the RIPPLES of Meaningful Involvement, with RIPPLES being an acronym for the seven key elements described above: Recognizing and Representing Indigenous Peoples, Interrupting and Re-Imagining Relationships, Preparing Agreements, Practicing Protocols, Leveraging Power, Exerting Community Authority, and Shifting Social Structures.

This framework illustrates the key elements of meaningful involvement along a continuum, which is represented by a series of concentric ripples. Each "ripple" radiating outwards represents a key element of meaningful involvement in which Indigenous Peoples are increasingly more influential. The progression of ripples further illustrates how a single effort towards increasing Indigenous representation could be seen an important first step towards more influential involvement. For example, if an Indigenous person is involved in a tokenizing way, although problematic, this could be a first drop in creating a series of ripples toward including Indigenous Peoples in ways that are non-tokenizing and, eventually, in ways where inclusion is at a deeper, structural level. This is the ripple effect of meaningful involvement; as Indigenous Peoples become increasingly influential in policy decision-making, the policy system itself becomes increasingly effective in addressing Indigenous health and social inequities.

The ripples are set against a backdrop of decolonization to illustrate how the enactment of each element from one ripple to the next may represent a transformative shift towards decolonization of the wider policy system. Each effort to include Indigenous Peoples in increasingly influential ways may work towards disrupting a Eurocentric and colonial policy system and contribute to the advancement of Indigenous Peoples' agendas and efforts towards sovereignty and self-determination. Drawing on Ritskes' (2012) construction of decolonization as a goal rather an endpoint, meaningful involvement may be a goal to work towards rather than an endpoint to be achieved. It is a process of ongoing reflection and taking action to deepen the ways in which Indigenous Peoples are involved, and subsequently deepening the extent to which policy processes can improve Indigenous Peoples' health and address health and social inequities. 


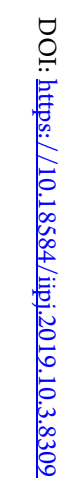

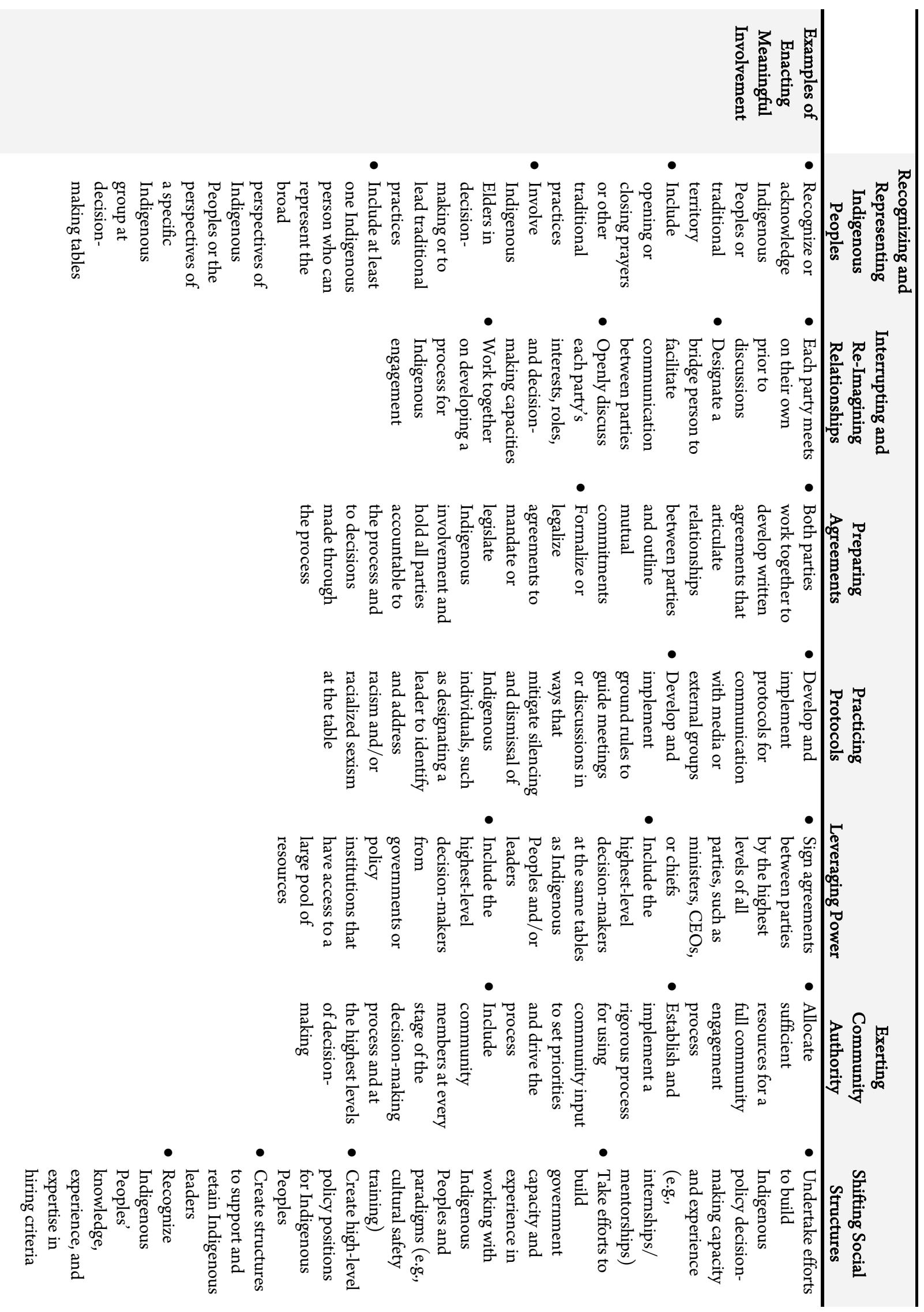




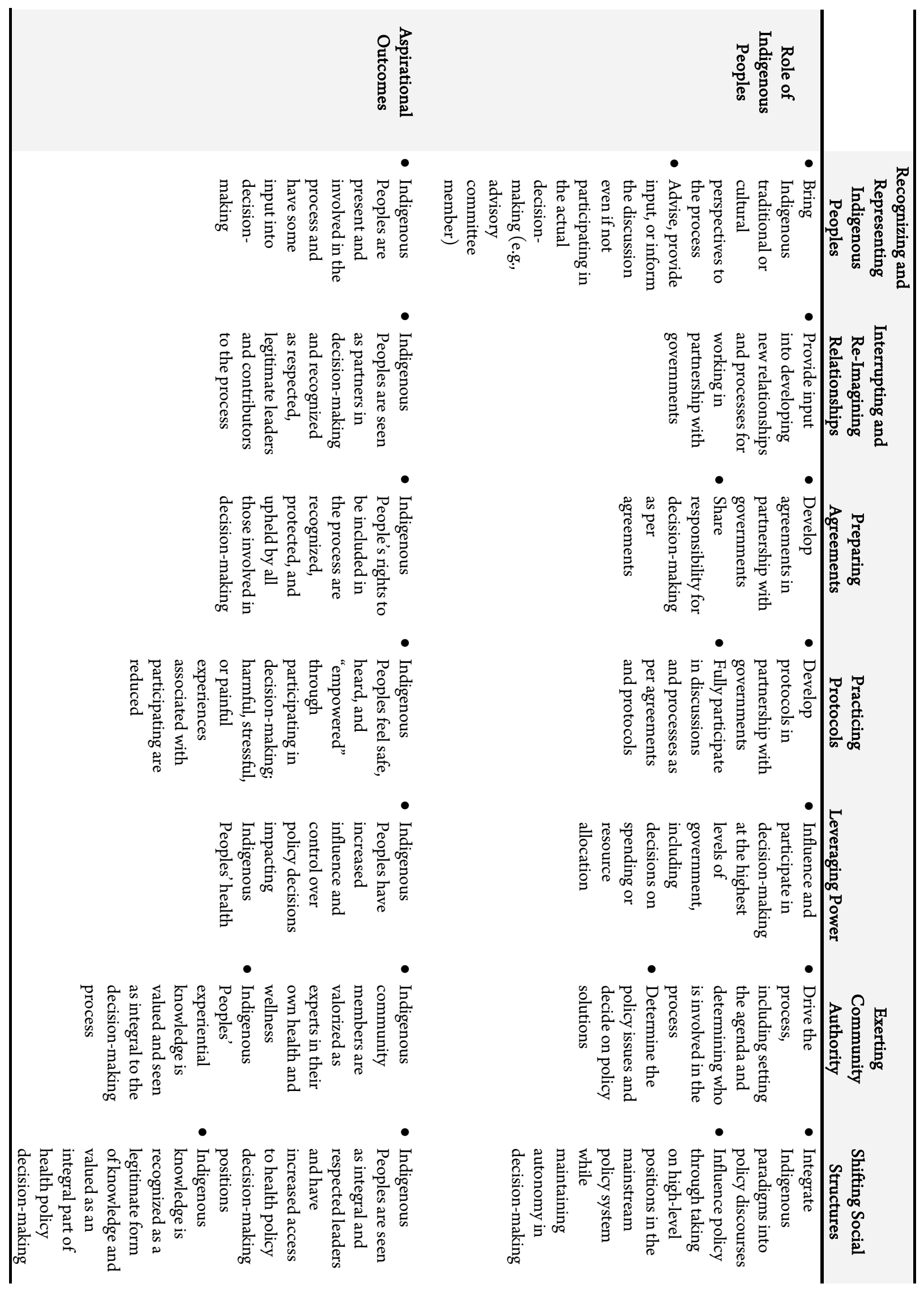




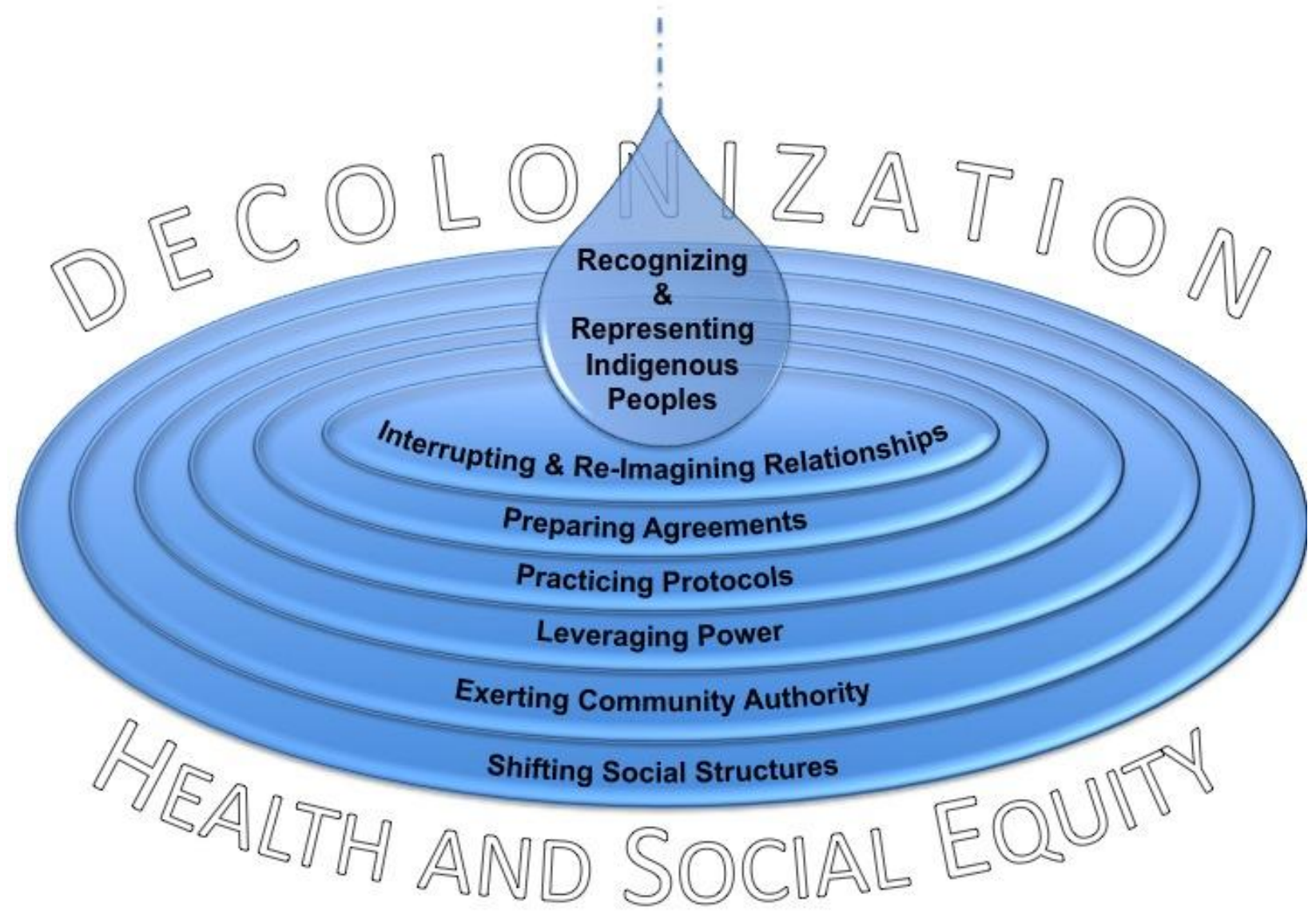

Figure 1. The RIPPLES of Meaningful Involvement

The RIPPLES of Meaningful involvement is offered as framework to inform policy, research, and other decision-making processes with respect to how Indigenous Peoples could be more meaningfully and influentially involved in a policy or decision-making process. This framework is not intended to be a "one-size-fits-all" model for how Indigenous Peoples should ideally be involved in every process. Instead, it is intended to be a heuristic device to stimulate further thinking and discussion on ways of meaningfully involving Indigenous Peoples in policy decision-making. We explicitly note that the intention of the RIPPLES framework is not to introduce a new dominant discourse or way of thinking about meaningful involvement that should remain unchallenged, unmodified, or withheld from further refinement, but to offer a starting place, or perhaps in some contexts a continuing place, for thinking about how more meaningful involvement could be realized and fostered.

\section{Limitations of the Research}

Consistent with the aims of qualitative inquiry, this study aims to make sense of and provide insight into a complex social problem (Leung, 2015). This has implications for the generalizability of the findings, in that the perspectives gleaned from the data are not intended to make inferences about meaningfully involving Indigenous Peoples in every health policy decision-making context; rather, the findings aim to 
provide insight into the broader question of how to foster meaningful involvement. In addition, while aligned with the overall paradigm of research in which all knowledge is considered to be socially constructed and imbued with inherent bias, the purposive sampling strategy may have contributed to recruitment of participants who share a similar set of experiences or perspectives, which could limit the range of experiences and perspectives that inform the findings.

\section{Conclusion}

To continue moving towards decolonization and more meaningful and influential involvement of Indigenous Peoples in health policy, efforts are needed to confirm that attention is paid to assessing and improving processes of involvement. This research may inform directions for future research, including investigating ways of evaluating and monitoring how Indigenous Peoples are involved in health policy decision-making and measuring the transformation towards meaningful involvement, particularly from the perspectives of Indigenous individuals who are involved in the process and also those who are impacted by the decisions. This research may inform future studies that aim to build on the findings, such as studies exploring rules for engagement or protocols that effectively counter racism and the silencing and dismissal of Indigenous Peoples at the decision-making table. Future studies could result in the development of indicators for meaningful involvement based on this framework, or applied tools for guiding health policy leaders in designing decision-making processes that foster and adopt more meaningful and influential involvement of Indigenous Peoples.

\section{References}

Anderson, J. (2000). Gender, 'race', poverty, health and discourses of health reform in the context of globalization: A postcolonial feminist perspective in policy research. Nursing Inquiry, 7(4), 220229. doi: https://doi.org/10.1046/j.1440-1800.2000.00074.x

Asher, K. (2017). Spivak and Rivera Cusicanqui on the dilemmas of representation in postcolonial and decolonial feminisms. Feminist Studies, 43(3), 512-524. doi: https://doi.org/10.15767/feministstudies.43.3.0512

Atleo, S. (2014, May 2). Shawn Atleo's statement of resignation. CBC News. Retrieved from https://www.cbc.ca/news/indigenous/shawn-atleo-s-statement-of-resignation-1.2630279

Australian Institute of Health and Welfare. (2015). The health and welfare of Australia's Aboriginal and Torres Strait Islander Peoples. Canberra: Australian Government.

Barbour, R. S. (2001). Checklists for improving rigour in qualitative research: A case of the tail wagging the dog? British Medical Journal, 322, 1115-1117. doi: https://doi.org/10.1136/bmj.322.7294.1115

Battiste, M. (2009). Maintaining Aboriginal identity, language, and culture in modern society. In M. Battiste (Ed.), Reclaiming Indigenous voice and vision (pp. 192-208). Vancouver: University of British Columbia Press. 
Battiste, M., \& Youngblood Henderson, J. (2000). Protecting Indigenous knowledge and heritage: A global challenge. Saskatoon, SK: Purich Publishing.

Belanger, Y., \& Walker, R. (2009). Interest convergence and co-production of plans: An examination of Winnipeg's 'Aboriginal Pathways.' Canadian Journal of Urban Research, 18(1), S118-139.

Blackstock, C. (2011). The Canadian Human Rights Tribunal on First Nations child welfare: Why if Canada wins, equality and justice lose. Children and Youth Services Review, 33, 187-197. doi: https://doi.org/10.1016/j.childyouth.2010.09.002

Browne, A., Smye, V., \& Varcoe, C. (2007). Postcolonial-feminist theoretical perspectives and women's health. In O. Hankivsky, C. Varcoe, \& M. Morrow (Eds.), Women's health in Canada: Critical perspectives on theory and policy (pp. 124-142). Toronto: ON: University of Toronto Press. doi: https://doi.org/10.3138/9781442685604-006

Browne, A., Varcoe, C., Lavoie, J., Smye, V., Wong, S., Krause, M., .. Fridkin, A. (2016). Enhancing health care equity with Indigenous populations: Evidence-based strategies from an ethnographic study. BMC Health Services Research, 16(544), 1-17. doi: https://doi.org/10.1186/s12913-016-1707-9

Brownridge, D. A. (2008). Understanding the elevated risk of partner violence against Aboriginal women: A comparison of two nationally representative surveys of Canada. Journal of Family Violence, 23, 353-367. doi: https://doi.org/10.1007/s10896-008-9160-0

Cheema, G. (2007). Aboriginal participation in health planning: Representation, reconciliation, and relationship-building with an Aboriginal advisory committee. In J. P. White, S. Wingert, D. Beavon \& P. Maxim (Eds.), Aboriginal policy research: Moving forward, making a difference (Vol. IV, pp. 17-38). Ottawa, ON: Thompson Educational Publishing.

Coulthard, G. (2014). Red skin, white masks: Rejecting the colonial politics of recognition. Minneapolis: University of Minnesota Press. doi: https://doi.org/10.5749/minnesota/9780816679645.001.0001

Davidson, A. (2008). Sweet nothings? The BC conversation on health. Healthcare Policy, 3(4), 33-40. doi: https://doi.org/10.12927/hcpol.2008.19917

Denizen, N. K., Lincoln, Y. S., \& Smith, L. T. (Eds.). (2008). Handbook of critical and Indigenous methodologies. Thousand Oaks, CA: SAGE Publications.

Diabo, R. (2014). Harper launches major First Nations termination plan: As negotiating tables legitimize Canada's colonialism. In the Kino-nda-niimi Collective (Ed.), The winter we danced: Voices from the past, the future, and the Idle No More movement (pp. 51-64). Winnipeg, MB: Arbeiter Ring Publishing.

Dion Stout, M. (2008). Spirit beads, resilience, and residential school. Visions Journal, 5(1), 11-12. doi: https://doi.org/10.12968/chca.2008.5.11.37335 
Dion Stout, M., \& Kipling, G. (1998). Aboriginal women in Canada: Strategic research directions for policy development. Ottawa: Status of Women Canada.

DiPenta, M. (2006). The Kelowna Accord: Closing the gap?Halifax, NS: Metro Coalition for a NonRacist Society.

Durbin, A. (2009). Canada's response to the on-reserve housing crisis: A study of the Kelowna Accord. Pimatisiwin, 7(2), 181-200.

Dwyer, J., O'Donnell, K., Willis, E., \& Kelly, J. (2016). Equitable care for Indigenous People: Every health service can do it. Asia Pacific Journal of Health Management, 11(3), 11-17. doi: https://doi.org/10.24083/apjhm.v1li3.143

Ermine, W. (1999). Aboriginal epistemology. In M. Battiste \& J. Barman (Eds.), First Nations education in Canada: The circle unfolds (pp. 101-112). Vancouver: University of British Columbia Press.

Ermine, W. (2007). The ethical space of engagement. Indigenous Law Journal, 6(1), 194-201.

First Nations Information Governance Centre. (2019). The First Nations principles of OCAP ${ }^{\circledR}$. doi: https://doi.org/10.1177/0840470415600131

Fiske, J.-A., \& Browne, A. J. (2008). Paradoxes and contradictions in health policy reform: Implications for First Nations women. Vancouver: British Columbia Centre of Excellence for Women's Health. Retrieved from http://bccewh.bc.ca/2014/02/paradoxes-and-contradictions-in-healthpolicy-reform-implications-for-first-nations-women/

Fridkin, A. (2012). Addressing health inequities through Indigenous involvement in health-policy discourses. Canadian Journal of Nursing Research, 44(2), 108-122.

Gallagher, J., Mendez, J., \& Kehoe, T. (2015). The First Nations Health Authority: A transformation in healthcare for BC First Nations. Healthcare Management Forum, 28(6), 255-261. doi: https://doi.org/10.1177/0840470415600131

Government of Canada. (2017). TCPS 2 (2014)-the latest edition of Tri-Council Policy Statement: Ethical conduct for research involving humans. Retrieved from http://www.pre.ethics.gc.ca/eng/policy-politique/initiatives/tcps2-eptc2/Default/

Howse, G., \& Dwyer, J. (2016). Legally invisible: Stewardship for Aboriginal and Torres Strait Islander health. Australian and New Zealand Journal of Public Health, 4O(Suppl. 1), S14-S20. doi: https://doi.org/10.1111/1753-6405.12358

Indigenous and Northern Affairs Canada. (2017). United Nations Declaration on the Rights of Indigenous Peoples. Retrieved from https://www.aadnc-aandc.gc.ca/eng/1309374407406/ $\underline{1309374458958}$

Irlbacher-Fox, S. (2009). Finding Dahshaa: Self-government, social suffering, and Aboriginal policy in Canada. Vancouver: UBC Press. 
Kelm, M. (1999). Colonizing bodies: Aboriginal health and healing in British Columbia, 1900-50. Vancouver: University of British Columbia Press. doi: https://doi.org/10.3138/cbmh.16.2.369

The Kino-nda-niima Collective. (2014). Idle No More: The winter we danced. In the Kino-nda-niima Collective (Ed.), The winter we danced: Voices from the past, the future, and the Idle No More movement (pp. 21-26). Winnipeg, MB: Arbeiter Ring Publishing.

LaRocque, E. (2010). When the Other is me: Native resistance discourse 1850-1990. Winnipeg: University of Manitoba Press. doi: https://doi.org/10.15695/amqst.v11i2.3973

Lavoie, J., Boulton, A. F., \& Gervais, L. (2012). Regionalization as an opportunity for meaningful Indigenous participation in healthcare: Comparing Canada and New Zealand. The International Indigenous Policy Journal, 3(1). doi: https://doi.org/10.1111/1753-6405.12358

Lavoie, J. G., Browne, A. J., Varcoe, C., Wong, S. T., Fridkin, A., Littlejohn, D., \& Tu, D. (2015). Missing pathways to self-governance: Aboriginal health policy in British Columbia. International Indigenous Policy Journal, 6(1), 1-18. doi: https://doi.org/10.18584/iipj.2015.6.1.2

Lavoie, J. G., Forget, E. L., Prakash, T., Dahl, M., Martens, P., \& O'Neil, J. D. (2010). Have investments in on-reserve health services and initiatives promoting community control improved First Nations' health in Manitoba? Social Science \& Medicine, 71, 717-724. doi: https://doi.org/10.1016/j.socscimed.2010.04.037

Lavoie, J., G., Kornelsen, D., Wylie, L., Mignone, J., Dwyer, J., Boyer, Y., .. O'Donnell, K. (2016). Responding to health inequities: Indigenous health system innovations. Global Health, Epidemiology and Genomics, 1. doi: https://doi.org/10.1017/gheg.2016.12

Leung, L. (2015). Validity, reliability, and generalizability in qualitative research. Journal of Family Medicine and Primary Care, 4(3), 324-327. doi: https://doi.org/10.4103/2249-4863.161306

Loppie Reading, C., \& Wien, F. (2009). Health inequalities and social determinants of Aboriginal Peoples' health. Prince George, BC: National Collaborating Centre for Aboriginal Health.

Matthews, A., Pulver, L., \& Ring, I. (2008). Strengthening the link between policy formulation and implementation of Indigenous health policy directions. Australian Health Review, 32(4), 613. doi: https://doi.org/10.1071/AH080613

McConaghy, C. (2000). Rethinking Indigenous education. Flaxton, Australia: Post Pressed.

McWilliams, C. (2004). Including the community in local regeneration? The case of Greater Pollok Social Inclusion Partnership. Local Economy: The Journal of the Local Economy Policy Unit, 19(3), 264. doi: https://doi.org/10.1080/0269094042000253185

Mitrou, F., Cooke, M., Lawrence, D., Povah, D., Mobila, E., Guimond, E., \& Zubrick, S. (2014). Gaps in Indigenous disadvantage not closing: A census cohort study of social determinants of health in 
Australia, Canada, and New Zealand from 1981-2006. BMC Public Health, 14(201), 1-9. doi: https://doi.org/10.1186/1471-2458-14-201

National Collaborating Centre for Aboriginal Health. (2013). Setting the context: An overview of Aboriginal health in Canada. Prince George, BC: National Collaboration Centre for Aboriginal Health.

Nelson, S. E., \& Wilson, K. (2017). The mental health of Indigenous Peoples in Canada: A critical review of research. Social Science \& Medicine, 176, 93-112.

doi: https://doi.org/10.1016/j.socscimed.2017.01.021

O'Neil, J. (1993). Aboriginal health policy for the next century. The path to healing: Royal Commission for Aboriginal Peoples (pp. 27-48). Ottawa, ON: Minister of Supply and Services Canada.

Oliver, V., Flicker, S., Danforth, J., Konsmo, E., Wilson, C., Jackson, R., . . Mitchell, C. (2015). Women are supposed to be the leaders': Intersections of gender, race and colonisation in HIV prevention with Indigenous young people. Culture, Health \& Sexuality, 17(7), 906-919.

doi: https://doi.org/10.1080/13691058.2015.1009170

Palmater, P. (2014). Why are we Idle No More? In the Kino-nda-niimi Collective (Ed.), The winter we danced: Voices from the past, the future, and the Idle No More movement (pp. 37-40). Winnipeg, MB: Arbeiter Ring Publishing.

Patterson, L. L. (2006). Aboriginal roundtable to Kelowna Accord: Aboriginal policy negotiations, 2004-2005. Ottawa: Parliamentary Information and Research Service, Library of Parliament.

Quantz, D., \& Thurston, W. E. (2006). Representation strategies in public participation in health policy: The Aboriginal Community Health Council. Health Policy, 75, 243-250.

doi: https://doi.org/10.1016/j.healthpol.2005.03.009

Rains, F. V., Archibald, J., \& Deyhle, D. (2000). Introduction: Through our eyes and in our own words. Qualitative Studies in Education, 13(4), 337-342. doi: https://doi.org/10.1080/095183900413287

Reading, J., \& Nowgesic, E. (2002). Improving the health of future generations: The Canadian Institutes of Health Research Institute of Aboriginal Peoples' Health. American Journal of Public Health, 92(9), 1396-1400. doi: https://doi.org/10.2105/AJPH.92.9.1396

Regan, P. (2005). A transformative framework for decolonizing Canada: A non-Indigenous approach. Paper presented at the Indigenous Governance Doctoral Student Symposium, Victoria, BC.

Richards, L., \& Morse, J. M. (2007). Readme first for a user's guide to qualitative methods ( $\left.2^{\text {nd }} \mathrm{ed}.\right)$. Thousand Oaks, CA: SAGE Publications. doi: https://doi.org/10.3316/qri0701067

Rigney, L.-I. (1999). Internationalization of an Indigenous anticolonial cultural critique of research methodologies: A guide to Indigenous research methodology and its principles. WicazoSa Review, 14(2), 109-121. doi: https://doi.org/10.2307/1409555 
Ritskes, E. (2012). What is decolonization and why does it matter? IC Magazine. Retrieved from https://intercontinentalcry.org/what-is-decolonization-and-why-does-it-matter/

Royal Commission on Aboriginal Peoples. (1996). Report of the Royal Commission on Aboriginal Peoples (Vol. 3, Gathering Strength). Ottawa, ON: Author.

Scott, C. (2019, March 1). Jody Wilson-Raybould comes from a long line of Indigenous truth-tellers. National Post. Retrieved from https://nationalpost.com/pmn/news-pmn/jody-wilsonraybould-comes-from-a-long-line-of-indigenous-truth-tellers

Smith, L. T. (1999). Decolonizing methodologies: Research and Indigenous Peoples. New York and Dunedin: Zed Books and University of Otago Press.

Smye, V., \& Browne, A. (2002). 'Cultural safety' and the analysis of health policy affecting Aboriginal People. Nurse Researcher, 9(3), 42. doi: https://doi.org/10.7748/nr2002.04.9.3.42.c6188

Thorne, S. (2008). Interpretive description. Walnut Creek, CA: Left Coast Press. doi: https://doi.org/10.4324/9781315426259

Truth and Reconciliation Commission of Canada. (2015a). Honouring the truth, reconciling for the future: Summary of the final report of the Truth and Reconciliation Commission of Canada. Retrieved from http://www.trc.ca/assets/pdf/Honouring the Truth_Reconciling for the Future July 23 2015.pdf

Truth and Reconciliation Commission of Canada. (2015b). Truth and Reconciliation Commission of Canada: Calls to Action. Retrieved from http://trc.ca/assets/pdf/Calls to Action_English2.pdf

Turner, D. (2006). This is not a peace pipe: Towards a critical Indigenous philosophy. Toronto, ON: University of Toronto Press.

United Nations. (2007). United Nations Declaration on the Rights of Indigenous Peoples (A/RES/61/295). Retrieved from http://www.un.org/development/desa/indigenouspeoples/wpcontent/uploads/sites/19/2018/11/UNDRIP_E_web.pdf

Walia, H. (2015). Decolonizing together: Moving beyond a politics of solidarity toward a practice of decolonization. In the Kino-nda-niima Collective (Ed.), The winter we danced: Voices from the past, the future, and the Idle No More movement (pp. 44-51). Winnipeg, MB: Arbeiter Ring Publishing.

Walker, R., Moore, J., \& Linklater, M. (2011). More than stakeholders, voices and tables: Towards coproduction of urban Aboriginal policy in Manitoba. In E. J. Peters (Ed.), Urban Aboriginal policy making in Canadian municipalities (pp. 160-201). Montreal, QC: McGill-Queen's University Press. 
Wien, F. (1999). The Royal Commission Report: Nine steps to rebuild Aboriginal economies. Journal of Aboriginal Economic Development, 1(1), 102-119. 